\title{
INDEX OF VOLUME 48
}

Subjects:

\author{
INDEX OF ABSTRACTS ${ }^{1}$
}

Algebra and Theory of Numbers, 29, 210, 355, 518, 665, 825 .

Analysis, 35, 212, 361, 519, 666, 827.

Applied Mathematics, 44, 216, 369, 522, 669, 831.

Geometry, 48, 216, 371, 522, 670, 833 .

Logic and Foundations, 49, 219, 373, 834.

Statistics and Probability, 52, 220, 374, 523, 673, 834 .

Topology, 52, 220, 374, 523, 675, 835.

Authors:

Adams, C. R., 805 (666); Albert, A. A., 7 (29), 336 (210), 502 (355); Albert, G. E., 806 (666); Allendoerfer, C. B., 192 (49); Arnold, B. H., 493 (355); Aroian, L. A., 805 (673); Artin, E., 502 (355); Avann, S. P., 9 (29), 9 (29), 495 (356), 496 (356).

Baer, R., 193 (29), 503 (356), 806 (518); Barker, C. B., 9 (35); Barnett, I. A., 192 (30); Basoco, M. A., (827); Beaumont, R. A., 496 (210); Beckenbach, E. F., $4(47 ; 705), 5$ (47; 862), 192 (36), 193 (36); Begle, E. G., 503 (374); Bell, P. O., 336 (216); Bergman, S., 191 (36), 336 (216), 492 (370), 493 (369), 806 (669), 806 (670); Berkeley, E. C., 193 (49); Bernstein, D. L., 501 (361); Berry, G. D. W., 193 (50); Bers, L., 4 (47; 860), 492 (362), (831); Birkhoff, G., (831); Blanch, G., 337 (213); Blumenthal, L. M:, 7 (48); Bochner, S., 191 (37), 193 (30); Bourgin, D. G., 4 (47; 711); Brauer, R., 493 (356); Bradshaw, J. W., 192 (37); Brown, A. B., 4 (47; 860); Brown, H. K., 806 (522); Bruck, R. H., 7 (47; 856), 191 (30), 193 (30), 195 (34); Busemann, H., 502 (371); Bushey, J. H., 492 (374), 493 (374), 493 (374).

Cairns, S. S., $4(47 ; 711), 4(47 ; 711)$; Cameron, R. H., (666); Campbell, A. D., 4 (47; 856); Carlitz, L., 193 (35), 493 (357), 806 (825), 806 (825); Church, A., 193 (50); Civin, P., 336 (220), 492 (376); Clarkson, J. A., 805 (666); Clippinger, R. F., 503 (357); Coburn, N., 9 (48), 336 (217), 336 (217), (832); Cohen, I. S., 193 (31); Cohen, L. W., 806 (828); Comenetz, G., 4 (47; 863); Court, N. A., 193 (48); Coxeter, H. S. M., 806 (670); Curtiss, J. H., $4(47 ; 710)$.

Davids, N., 5 (47; 704); Day, M. M., 503 (375); DeCicco, J. J., 4 (47; 863), 336 (217), 336 (218), 336 (218), (670), 806 (671), 807 (672), (833); Dilworth, R. P., 9 (31), 9 (31), 191 (31), 493 (357), 805 (825); Dines, L. L., 193 (210); Doob, J. L., 193 (37); Douglas, J., 336 (218); Dressel, F. G., 493 (362).

Eilenberg, S., 193 (54), 805 (836); Engelbrecht, A. E., 7 (44); Erdös, P., 805 (666);

Ettlinger, H. J., 193 (37); Everett, C. J., 807 (522), (826); Ewing, G. M., 501 (364).

Feller, W., 807 (828); Fialkow, A., 493 (372); Ficken, F. A., 493 (357); Flexner, W. W., 192 (52); Foote, W. R., 806 (832); Forsythe, G. E., 495 (212); Fort, T., 192 $(47 ; 857)$; Frame, J. S., 493 (357).

Garabedian, H. L., 336 (212); Gaskell, R. E., 193 (45); Geiringer, H. P., 492 (370); Gelbart, A., 193 (37), 336 (212), 493 (371), (831); Gere, B. H., 807 (671); Goodman, N., 193 (50); Gordon, R. D., 9 (52); Gottschalk, W. H., 807 (523); Greenberg, H. J., 336 (212); Greville, T. N. E., 805 (834); Gumbel, E. J., 4 (47; 865), 805 (673).

Hall, D. W., 194 (53), 806 (675); Hall, M., 191 (31); Halmos, P. R., 493 (523);

1 Numbers within parentheses refer to the page numbers for abstracts, and those outside parentheses refer to the pages for titles as listed in reports of meetings. 
Harrold, O. G., 807 (835); Heins, A. E., 192 (45); Hellinger, E. D., 502 (362); Hildebrand, F. B., 194 (45); Hille, E., 9 (38), 495 (519), 806 (828); Hillman, A., 337 (213), 494 (363), (828); Hinrichsen, J. J. L., 7 (45); Holl, D. L., 6 (46); Horenstein, W., 5 (47; 861), 337 (213); Hughes, H. K., 502 (364); Hurewicz, W., 493 (519); Hutchinson, L. C., 493 (372); Hyers, D. H., 502 (368).

Isaacs, R. P., (832).

Jacobson, N., 493 (518); James, R. C., 8 (53), 9 (53), 495 (375); James, R. D., 502 (358); John, F., 501 (362); Johnson, R. E., 502 (358); Jonah, H. F. S., 502 (358); Jones, B. W., 4 (32); Jones, F. B., 194 (220), 806 (836).

Kac, M., 192 (38); 807 (667), 807 (673); Kales, M. L., 503 (363); Kaplan, S., 503 (375); Kaplansky, I., 194 (32), 337 (220), (826), (826); Karlin, M., 493 (363); Karush; W., 501 (519); Kasner, E., 336 (218), 337 (219), (671), (672), 806 (672), 807 (672), (833); Kelley, J. L., 192 (221); Kempner, A. J., 807 (826); Kershner, R. B., 192 (38); Kincaid, W. M., 807 (675); Kleene, S. C., 193 (51), 493 (373); Kogbetliantz, E., (829); Korn, A., 4 (47; 863); Krabill, D. M., 807 (829).

Laden, H. N., 194 (38); Lehmer, D. H., 8 (47; 857), 807 (665); Lehner, J., 194 (35), 493 (358); Leighton, W., 496 (213), 503 (213), 807 (520); Levi, H., 5 (47; 857); Levenson, A., 5 (47; 704); Levit, R. J., 8 (47; 857); Lewis, F. A., 493 (359); Lorch, E. R., 336 (47; 860); Lorch, L., 807 (829); Lowan, A. N., 5 (47; 704); 5 (47; 861), 337 (213), 337 (213), 494 (363), (520); Lubben, R. G., 807 (675)

McEwen, G. F., 9 (52); McShane, E. J., 194 (39), 194 (39); MacDuffee, C. C., 191 (32); Mackey, G. W., 8 (47; 861); MacLane, S., 192 (32), 193 (54), 805 (836); Maker, P. T., 191 (39); Mandelbrojt, S., 807 (520), (829); Mann, H. B., 336 (211), 805 (674), (834); Marth, E., 807 (667); Martin, W. T., 191 (37), (666); Mendel, C. W., 192 (30); Menger, K., 807 (833), 807 (833); Mersman, W. A., 495 (371), 496 (371); Michal, A. D., 496 (372); Mickle, E. J., 191 (39); Milgram, A. N., 503 (375); Miller, H. C., 192 (54); Miller, G. T., 502 (364); Millsaps, K., 9 (54), 496 (359); Mitchell, J. M., 807 (667); Mittleman, D., 337 (219), 337 (372); Montgomery, D., 806 (676), 807 (676), 808 (676); Moore, R. L., 808 (836), 808 (836); Morkovin, V., 806 (670); Morse, A. P., 805 (666); Morse, M., 501 (364), 808 (521); Munro, G. C., 7 (39); Munroe, M. E., 804 (521); Myers, S. B., 194 (39).

Nesbitt, C. J., 193 (34); Nielsen, K. L., 336 (214), 808 (668); Niven, I., 502 (359).

Oboukhoff, N. M., 194 (40); O'Connor, R. E., 5 (47; 858); 5 (47; 859), 5 (47; 859); Oldenburger, R., 493 (360), 494 (359), 502 (359); Opatowski, I., 7 (46), 502 (364); Owens, O. G., 9 (40).

Pall, G., 805 (827), 808 (827); Pate, R. S., 7 (32); Paydon, J. F., 194 (40); Pepper, P. M., 502 (373); Perlis, S., 194 (33); Peters, J. W., 192 (49); Phillips, R. S., 193 (30); Pinney, E. J., 9 (41), 496 (365), 496 (365); Pollard, H., 5 (47; 700), 336 (214), 494 (365), 494 (365); Polya, G., 503 (366); Poritsky, H., 806 (832); Prager, W., 192 (46); Prenowitz, W., 4 (47; 864).

Rademacher, H. A., 494 (366); Rado, T., 501 (366); Rainich, G. Y., 193 (41); Ramsey, B. P., 808 (668); Reade, M., 5 (47; 862), 192 (36), 194 (41); Reichelderfer, P. V., 501 (366); Reid, W. T., 806 (829); Reves, G. E., 191 (42); Reynolds, C. N., 808 (836); Ritt, J. F., 5 (47; 862), (827); Roberts, J. H., 492 (376); Robinson, C. V., 7 (47; 864); Robinson, R. M., 9 (42), (830); Rochford, M. D. P., 808 (521), 808 (521); Roever, W. H., 194 (219), 502 (367); Rommel, J. D., 502 (522); Rosenbloom, P. C., 805 (830), Ross, A. E., 502 (518); Rosser, B., 193 (51).

Sadowsky, M. A., 503 (360); Salem, R., 336 (214), 805 (522), 808 (668); Salzer, H. E., 494 (363), (520), (828); Samelson, H., 493 (523), 806 (676), 807 (676); Satterthwaite, F. E., 805 (674); Schaeffer, A. C., 495 (212), (215); Schafer, R. D., 502 (360); 
Schatten, R., 4 (47; 862); Scheffé, H., 805 (523), 808 (674); Scherk, P., 502 (355); Schilling, O. F. G., 192 (32), 194 (32), 194 (33); Schwartz, H. M., 194 (42), 503 (367); Schweitzer, A. R., 5 (47; 709), 194 (51), 337 (211), 503 (219), 503 (220), 808 (834); Schwerdtfeger, H., 808 (519); Shanks, M. E., 7 (54); Shiffman, M., 808 (830); Shohat, J. A., (831); Silverman, L. L., 336 (215); Slade, J. J., 806 (832); Smiley, D. M., 808 (665); Smiley, M. F., 191 (33), 194 (211), 494 (360), 494 (367), 808 (367); Snapper, E., 4 (47; 858), (827); Snyder, W. S., 501 (368); Sorgenfrey, R. H., 194 (55); Spencer, D. C., 805 (522); Spencer, D. E., 805 (672); Struik, S. R. R., 805 (674), 805 (834), 808 (833); Swain, R. L., 503 (376); Swingle, P. M., 9 (55); Synge, J. L. 192 (47); Szász, O., 191 (42), 192 (42), 336 (215), 492 (368), 805 (668); Szegö, G., 9 (43), 806 (828).

Theilheimer, F., 192 (47); Thorne, C. J., 805 (668); Thrall, R. M., 193 (34), 503 (360); Thron, W. J., 496 (213), 503 (213), 807 (520); Thurston, H. S., 808 (665); Titt, E. W., 194 (43); Tomlinson, T. W., 502 (372); Tompkins, C. B., 502 (373); Topel, B. J., 502 (373); Transue, W. R., 191 (33), 192 (43), 494 (360); Tripp, R. H., 7 (47); Trjitzinsky, W. J., 194 (43); Tuan, H. F., 493 (356).

Ulam, S. M., 195 (44), 501 (361), 502 (368); Ulrich, F. E., 807 (520).

Valentine, F. A., 495 (368); Vanderslice, J. L., 192 (49); Villars, D. S., 805 (675); Vinograde, B., 502 (361).

Wade, T. L., 7 (47; 856), 195 (34); Wagner, R. W., 502 (361); Wald, A., 805 (674), 805 (835); Wall, H. S., 5 (47; 863), 194 (40), 336 (212), 502 (362); Wallace, A. D., 195 (221), 808 (524), (837); Wallman, H., 193 (216); Walsh, J. L., 494 (368); Ward, M., 8 (34); Wasow, W., 336 (215); van Waters, M., 805 (674); Webster, M. S., 503 (369); Weil, A., 192 (49); Weinstein, A., 193 (47), 337 (216); Weyl, H., 492 (369), 808 (669); White, P. A., 195 (55); Whitehead, G. W., 192 (55); Whitman, P. M., 192 (34); Whitney, H., 806 (676), 808 (676), 809 (669), 809 (669), 809 (669), 809 (677); Whyburn, G. T., 494 (376), 494 (376), 494 (376), 809 (837); Wilcox, L. R., 195 (35);

Wilkins, J. E., 502 (373); Wolf, F., 9 (44), 501 (369); Wolfowitz, J., 805 (835).

Youngs, J. W. T., 7 (47; 715), 503 (377), 806 (837).

Zippin, L., 808 (676); Zupnick, D., 807 (671).

\section{INDEX OF REPORTS OF MEETINGS AND MISCELLANEOUS ARTICLES}

Ayres, W. L. Reports of meetings of the American Mathematical Society: November meeting in Manhattan, 6; April meeting in Chicago, 496.

Birkhoff, G., MacLane, S., and Ore, O. Conference on Algebra and Twenty-Third Colloquium, 169.

Field, P. James Waterman Glover-In Memoriam, 199.

Goldstine, H. H., and Graves, L. M. Conference on the Theory of Integration, 175.

Graves, L. M. See Goldstine, H. H.

Hedrick, E. R. A Proposed Journal of Applied Mathematics, 791.

Hollcroft, T. R. Reports of meetings of the American Mathematical Society: October meeting in New York, 3; Annual meeting of Society, 183; February meeting in New York, 335; A pril meeting in New York, 491; Summer meeting in Poughkeepsie, 800.

Kline, J. R. See Morse, M.

MacLane, S. See Birkhoff, G.

Michal, A. D. Reports of meetings of the American Mathematical Society: April meeting in Berkeley, 495.

Morse, M. Letter from Marston Morse, 1.

Morse, M., and Kline, J. R. Occupational Classification of Mathematicians, 792. 
Murphy, R. D., and Richardson, R. G. D. Robert Henderson-In Memoriam, 504.

Occupational Bulletin No. 10, 797; Occupational Bulletin No. 23, 795.

Ore, O. See Birkhoff, G.

Putnam, T. M. Reports of meetings of the American Mathematical Society: November meeting in Pasadena, 8.

Richardson, R. G. D. See Murphy, R. D.

Selective Service, 795, 797

\section{INDEX OF BOOK REVIEWS}

Ayres, W. L. See Wilder, R. L.

Bateman, H. See Carslaw, H. S.

Bell, E. T. See Courant, R.

Bergman, S. Sur les Fonctions Orthogonales de Plusieurs Variables Complexes, avec les Applications â la Théorie des Fonctions Analytiques. A. Gelbart, 15.

Biernacki, M. Les Fonctions Multivalentes. (Actualités Scientifiques et Industrielles, no. 657.) W. Seidel, 640.

Biot, M. A. See von Kármán, T.

Birkhoff, G., and MacLane, S. A Survey of Modern Algebra. R. M. Thrall, 342.

Bourgin, D. G. See Conway, A. W.

Brauer, R. See Hancock, H.

Carslaw, H. S., and Jaeger, J. C. Operational Methods in Applied Mathematics. H. Bateman, 510 .

Churchill, R. V. See Research-A National Resource.

Conway, A. W., and McConnell, A. J., edited by. The Mathematical Papers of Sir William Rowan Hamilton. Vol. II. Dynamics. (Cunningham Memoir, no. 14.) D. G. Bourgin, 813.

Coulson, C. A. Waves. A Mathematical Account of the Common Types of Wave Motion. S. A. Schelkunoff, 202.

Courant, R., and Robbins, H. What is Mathematics? E. T. Bell, 810.

Curry, H. B. See Tarski, A.

Davis, H. T. The Analysis of Economic Time Series. (Cowles Commission for Research in Economics, Monograph, no. 6.) G. Tintner, 338.

Eisenhart, L. P. An Introduction to Differential Geometry with Use of the Tensor Calculus. G. A. Hedlund, 18.

Enzyklopädie der mathematischen Wissenschaften mit Einschluss ihrer Anwendungen. Band I, Teil 1, Heft 2; Band $I_{1}$, Teil 1, Heft 4; Band $I_{1}$, Heft 5. O. Ore, 653.

Gelbart, A. See Bergman, S.

Halmos, P. R. See Murray, F. J.

Hancock, H. Development of the Minkowski Geometry of Numbers. R. Brauer, 651.

Hazeltine, A. See von Kármán, T.

Hedlund, G. A. See Eisenhart, L. P.

Hurewicz, W., and Wallman, H. Dimension Theory. (Princeton Mathematical Series, no. 4.) P. A. Smith, 641.

Jaeger, J. C. See Carslaw, H. S.

James, R. D. See Lehmer, D. H.

von Kármán, T., and Biot, M. A. Mathematical Methods in Engineering. A. Hazeltine, 646.

Lehmer, D. H. Guide to Tables in the Theory of Numbers. R. D. James, 201.

McConnell, A. J. See Conway, A. W.

MacLane, S. See Birkhoff, G. 
Murray, F. J. An Introduction to Linear Transformations in Hilbert Space. (Annals of Mathematics Studies, no. 4.) P. R. Halmos, 204.

See Widder, D. V.

National Research Council. See Research-A National Resource.

Neyman, J. See Wald, A.

Opatowski, I. See Tables of the Moments of Inertia and Section Modulus of Ordinary Angles, Channels and Bulb Angles with Certain Plate Combinations.

Ore, O. See Enzyklopädie.

Poritsky, H. See Seth, B. R.

Quine, W. V. Mathematical Logic. B. Rosser, 21.

Research-A National Resource. II. Industrial Research. (Report of the National Research Council.) R. V. Churchill, 338.

Robbins, H. See Courant, R.

Rosser, B. See Quine, W. V.

Schelkunoff, S. A. See Coulson, C. A.

Schilpp, P. A., edited by. The Philosophy of Alfred North Whitehead. (The Library of Living Philosophers, vol. 3.) A. R. Turquette, 506.

Seidel, W. See Biernacki, M.

Seth, B. R. Two-dimensional Potential Problems Connected with Rectilinear Boundaries. H. Poritsky, 510.

Skolem, T. Diophantische Gleichungen. (Ergebnisse der Mathematik und ihrer Grenzgebiete, Band 5, Heft 4.) H. S. Vandiver, 10.

Smith, P. A. See Hurewicz, W.

Snyder, V. See Tables of Probability Functions.

Tables of the Moments of Inertia and Section Modulus of Ordinary Angles, Channels and Bulb Angles with Certain Plate Combinations. I. Opatowski, 813.

Tables of Probability Functions. Vol. 1, V. Snyder, 201.

Tarski, A. Introduction to Logic and to the Methodology of Deductive Sciences. H. B. Curry, 507.

Thrall, R. M. See Birkhoff, G.

Tintner, G. See Davis, H. T.

Turquette, A. R. See Schilpp, P. A.

Vandiver, H. S. See Skolem, T.

Wald, A. On the Principles of Statistical Inference. (Notre Dame Mathematical Lectures, no. 1.) J. Neyman, 639.

Wallman, H. See Hurewicz, W.

Walker, R. J. See Wilder, R. L.

Widder, D. V. The Laplace Transform. (Princeton Mathematical Series, no. 6.) F. J. Murray, 642.

Wilder, R. L., and Ayres, W. L., edited by. Lectures in Topology. (The University of Michigan Conference of 1940.) R. J. Walker, 203.

\section{INDEX OF ADDRESSES}

Bewley, L. V. Traveling waves on electric power systems, 527.

Boas, R. P. Entire functions of exponential type, 839.

Carlitz, L. Some topics in the arithmetic of polynomials, 679.

Hestenes, M. R. The problem of Bolza in the calculus of variations, 57.

Murray, F. J. The analysis of linear transformations, 76.

Rademacher, H. Trends in research: The analytic number theory, 379.

Sokolnikoff, I. S. Some new methods of solution of two-dimensional problems in elasticity, 539. 
Stoker, J. J. Mathematical problems connected with the bending and buckling of elastic plates, 247.

Whyburn, W. M. Differential equations with general boundary conditions, 692.

Wright, S. Statistical genetics and evolution, 223.

Zariski, O. Normal varieties and birational correspondences, 402.

\section{INDEX OF RESEARCH PAPERS}

Albert, A. A. The radical of a non-associative algebra, 891.

Aucoin, A. A. Homogeneous and nonhomogeneous Diophantine equations, 933.

Ayres, W. L. A new proof of the cyclic connectivity theorem, 627.

Baer, R. Inverses and zero-divisors, 630.

Barnard, R. W., and Goldstine, H. H. The modular space determined by a positive function, 946.

Bartels, R. C. F., and Churchill, R. V. Resolution of boundary problems by the use of a generalized convolution, 276.

Beaumont, R. A. Projections of the prime-power abelian group of order $p^{m}$ and type $(m-1,1), 866$.

Beckenbach, E. F. Vector analogues of Morera's theorem, 937.

Bewley, L. V. See Index of Addresses.

Blanch, G. See Lowan, A. N.

Boas, R. P. Generalized Laplace integrals, 286.

- See Index of Addresses.

Botts, T. On convex sets in linear normed spaces, 150.

Brauer, R. On the nilpotency of the radical of a ring, 752.

Bruck, R. H. Generalized Fischer groups and algebras, 618.

Carlitz, L. See Index of Addresses.

Carruth, P. W. Arithmetic of ordinals with applications to the theory of ordered abelian groups, 262.

Chevalley, C. On the composition of fields, 482 .

Churchill, R. V. Expansions in series of non-orthogonal functions, 143.

- See Bartels, R. C. F.

Clark, C. E. On 3-dimensional manifolds, 437.

Coleman, R. Conformal geometry of one-parameter families of curves, 94.

Court, N. A. On the theory of the tetrahedron, 583.

Davids, N. See Lowan, A. N.

Daum, J. A. The basic analogue of Kummer's theorem, 711.

DeCicco, J. See Kasner, E.

Dimsdale, B. Approximation of continuous functions by means of lacunary polynomials, 608.

Dines, L. L. On the mapping of $n$ quadratic forms, 467.

Dresden, A. On the iteration of linear homogeneous transformations, 577.

- A correction to "On the iteration of linear homogeneous transformations," 949.

Duffin, R. J., and Eachus, J. J. Some notes on an expansion theorem of Paley and Wiener, 850 .

Eachus, J. J. See Duffin, R. J.

Everett, C. J. Vector spaces over rings, 312.

Feld, J. M. Whirl-similitudes, euclidean kinematics, and non-euclidean geometry, 783.

Fialkow, A. Correction to "Totally geodesic Einstein spaces," 167.

Forsythe, G. E., and Schaeffer, A. C. Remarks on regularity of methods of summation, 863. 
Fort, T. Generalizations of the Bernoulli polynomials and numbers and corresponding summation formulas, 567.

- An addition to "Generalizations of the Bernoulli polynomials and numbers and corresponding summation formulas," 949.

Fox, R. H. A characterization of absolute neighborhood retracts, 271.

Gage, W. H. An arithmetical identity for the form $a b-c^{2}, 898$.

Garabedian, H. L. Hausdorff methods of summation which include all of the Cesiro methods, 124.

Goldstine, H. H. See Barnard, R. W.

Greenberg, H. J., and Wall, H. S. Hausdorff means included between $(C, 0)$ and $(C, 1)$, 774.

Griffiths, L. W. A note on representation by polygonal numbers, 122.

Harrold, O. G. A mapping characterization of Peano spaces, 561.

Hestenes, M. R. See Index of Addresses.

Hill, J. D. Some theorems on subseries, 103.

Hillman, A. See Lowan, A. N.

Horenstein, W. See Lowan, A. N.

Hua, L. K. On the least primitive root of a prime, 726.

- On the least solution of Pell's equation, 731.

Ingram, W. H. Forced oscillations of continuous dynamical systems, 153.

Jackson, D. Generalization of a theorem of Korous on the bounds of orthonormal polynomials, 602.

Jeffery, R. L. Perron integrals, 714.

Jones, B. W. An extension of a theorem of Witt, 133.

Jones, F. B. Connected and disconnected plane sets and the functional equation $f(x)+f(y)=f(x+y), 115$.

- Measure and other properties of a Hamel basis, 472.

Kaplansky, I., and Schilling, O. F. G. Some remarks on relatively complete fields, 744 .

Kasner, E., and DeCicco, J. Pseudo-conformal geometry: functions of two complex variables, 317.

Kober, H. A note on Hilbert's operator, 421.

Leighton, W., and Thron, W. J. On value regions of continued fractions, 917.

Levenson, A. See Lowan, A. N.

Lewis, F. A. Generators of permutation groups simply isomorphic with $L F\left(2, p^{n}\right), 907$.

Loomis, L. H. On an inequality of Seidel and Walsh, 908.

Lowan, A. N., Blanch, G., and Horenstein, W. On the inversion of the q-series associated with Jacobian elliptic functions, 737.

Lowan, A. N., Davids, N., and Levenson, A. Table of the zeros of the Legendre polynomials of order 1-16 and the weight coefficients for Gauss' mechanical quadrature formula, 739.

Lowan, A. N., Salzer, H. E., and Hillman, A. A table of coefficients for numerical differentiation, 920.

McShane, E. J. On Perron integration, 718.

MacLane, S., and Schilling, O. F. G. A formula for the direct product of crossed product algebras, 108.

Maker, P. T. The Cauchy theorem for functions on closed sets, 912.

Montgomery, D., and Zippin, L. A theorem on Lie groups, 448.

Murray, F. J. See Index of Addresses.

Nichols, G. D. A sufficient condition for Cesàro summability, 580. 
Patterson, J. O. A note on the diophantine problem of finding four biquadrates whose sum is a biquadrate, 736.

Peebles, G. H. On equivalence of certain types of series of orthonormal functions, 556.

Perlin, I. E. Sufficient conditions that polynomials in several variables be positive, 458 .

Perlis, S. A characterization of the radical of an algebra, 128.

Rademacher, H. See Index of Addresses.

Riblet, H. J. Factorization of differential ideals, 575.

- Symmetric differential expressions, 871.

Rosenthal, A. On differentiation of integrals and approximate continuity, 414.

Salzer, H. E. See Lowan, A. N.

Sanders, S. T. A linear transformation whose variables and coefficients are sets of points, 440.

Sard, A. The measure of the critical values of differentiable maps, 883.

Schaeffer, A. C. See Forsythe, G. E.

Schilling, O. F. G. See Kaplansky, I.; MacLane, S.

Schoenberg, I. J. On local convexity in Hilbert space, 432.

Scott, W. A note on the lower semi-continuity of double integrals in the parametric form, 763.

Shah, S. M. On integral functions of integral or zero order, 329.

Shohat, J. Note on closure for othogonal polynomials, 488.

Simmons, H. A. Classes of maximum numbers associated with two symmetric equations, 295.

Smith, P. A. Everywhere dense subgroups of Lie groups, 309.

Snyder, W. S. A remark on the cardinal of limit spaces, 121.

Sokolnikoff, I. S. See Index of Addresses.

Sprague, A. H. A differential geometry problem using tensor analysis, 747.

Springer, C. E. Dual geodesics on a surface, 901.

Stoker, J. J. See Index of Addresses.

Szász, O. On the logarithmic means of rearranged partial sums of a Fourier series, 705. Thron, W. J. See Leighton, W.

Vest, M. L. A non-involutorial space transformation associated with a $Q_{1, n}$ congruence, 767.

Non-involutorial space transformations associated with a linear congruence, 874.

Wade, T. L. Euclidean concomitants of the ternary cubic, 589.

Wall, H. S. The behavior of certain Stieltjes continued fractions near the singular line, 427.

See Greenberg, H. J.

Walsh, J. L. Note on the coefficients of overconvergent power series, 163.

Weisner, L. Roots of certain classes of polynomials, 283.

Whyburn, G. T. On the interiority of real functions, 942.

Whyburn, W. M. See Index of Addresses.

Wilcox, L. R. A note on complementation in lattices, 453.

Williamson, J. A generalization of the polar representation of nonsingular matrices, 856.

Wintner, A. On a family of Fourier transforms, 304.

- On an elementary analogue of the Riemann-Mangoldt formula, 759.

Wolf, F. On majorants of subharmonic and analytic functions, 925.

Wright, S. See Index of Addresses.

Zariski, O. See Index of Addresses.

Zippin, L. See Montgomery, D. 